Supporting information for:

\title{
Characterizing and controlling nanoscale self-assembly of suckerin-12
}

Jasmine M. Hershewe, William D. Wiseman, James E. Kath, Chelsea C. Buck, Maneesh K. Gupta, Patrick B. Dennis, Rajesh R. Naik, and Michael C. Jewett

Contents:

Figure S1. Determination of pAzF mutation site in S12

Figure S2. Optimized inclusion body preparation of S12

Figure S3. SPAAC reactions proceed in water and in $1 \%$ acetic acid

Figure S4. pH-dependence of S12 solubility in various salts is anion-dependent

Figure S5. Optimization of NA fabrication conditions

Figure S6. Optimization of NA fabrication conditions, continued

Figure S7. Further characterization of NAs fabricated with optimized conditions

Figure S8. Characterization of S12-PEG conjugates

Supporting Information methods: CryoTEM, Expression of S12 variants for determining a pAzF mutation position 


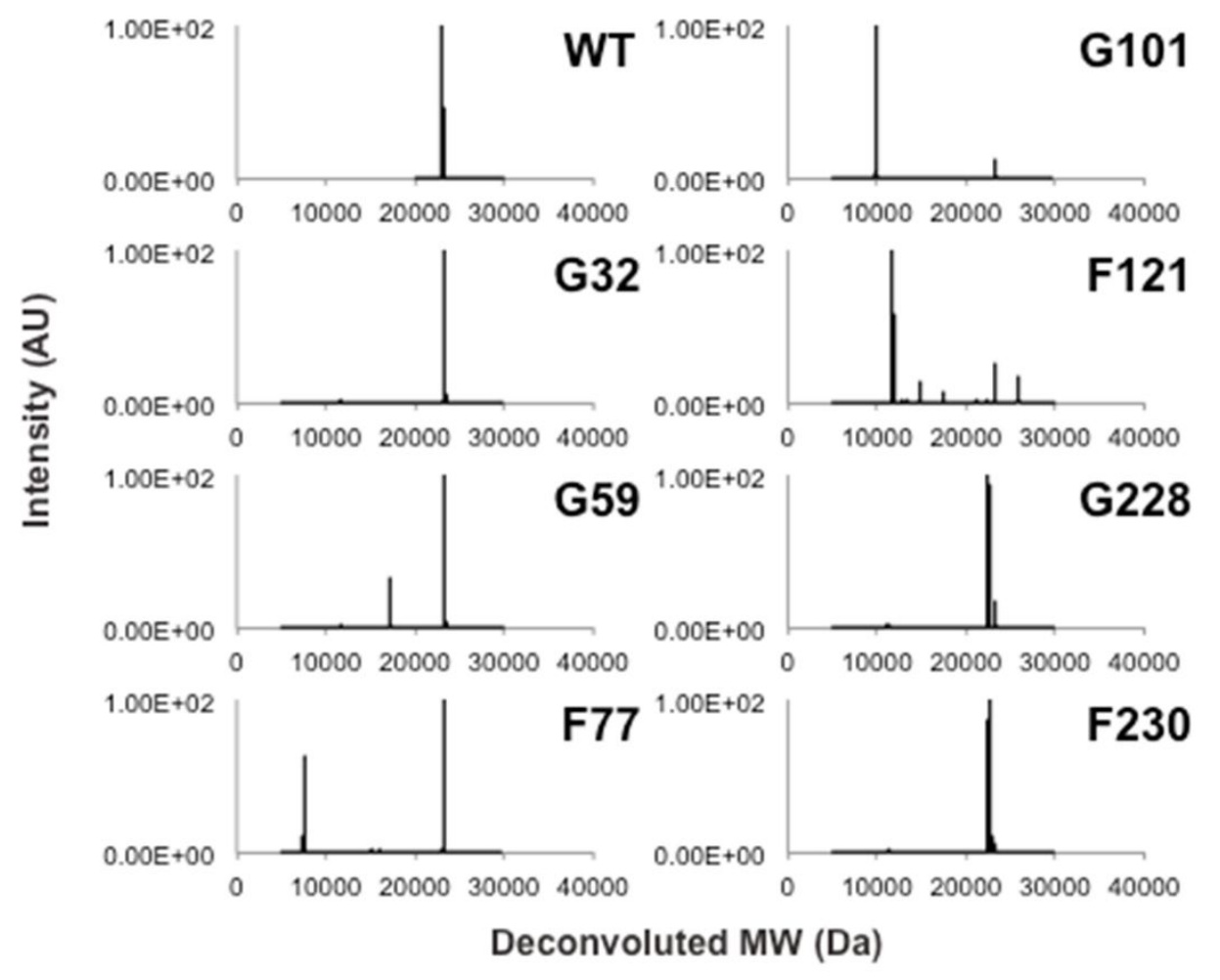

Figure S1. Determination of pAzF mutation site in S12. Deconvoluted liquid chromatography mass spectrometry (LC-MS) spectra of purified S12 mutants is presented. The inset of each trace shows the position that was mutated to pAzF. Amino acids glycine and phenylalanine are abbreviated $G$ and $F$, respectively. WT contained no pAzF substitutions. In all spectra other than for the G32 mutant, large peaks from truncation contaminants, which likely arise from Release Factor-1 (RF-1) competition with the amber suppressor tRNA, were observed. 
A

\begin{tabular}{|c|c|c|}
\hline Well Number & Well Contents & $\begin{array}{l}\text { Dilution } \\
\text { Factor }\end{array}$ \\
\hline 1 & Standard & - \\
\hline 2 & $\begin{array}{c}\text { Whole Cell } \\
\text { Resuspension } \\
\text { (Pre-lysis) }\end{array}$ & 10 \\
\hline 3 & $\begin{array}{l}\text { Post-lysis } \\
\text { Supernatant }\end{array}$ & - \\
\hline 4 & $\begin{array}{l}\text { Triton X-100 Wash } 1 \\
\text { Resuspension }\end{array}$ & 10 \\
\hline 5 & $\begin{array}{c}\text { Triton X-100 Wash } 1 \\
\text { Supernatant }\end{array}$ & - \\
\hline 6 & $\begin{array}{l}\text { Triton X-100 Wash } 2 \\
\text { Resuspension }\end{array}$ & 10 \\
\hline 7 & $\begin{array}{c}\text { Triton X-100 Wash } 2 \\
\text { Supernatant }\end{array}$ & - \\
\hline 8 & $\begin{array}{l}\text { Triton X-100 Wash } 3 \\
\text { Resuspension }\end{array}$ & 10 \\
\hline 9 & $\begin{array}{c}\text { Triton X-100 Wash } 3 \\
\text { Supernatant }\end{array}$ & - \\
\hline 10 & $\begin{array}{l}\text { No Triton Wash } \\
\text { Resuspension }\end{array}$ & 10 \\
\hline 11 & $\begin{array}{l}\text { No Triton Wash } \\
\text { Supernatant }\end{array}$ & - \\
\hline 12 & $\begin{array}{l}\text { Water Wash } \\
\text { Resuspension }\end{array}$ & 10 \\
\hline 13 & $\begin{array}{l}\text { Solubilized Suckerin-12 } \\
\text { (Post-high speed spin) }\end{array}$ & 10 \\
\hline 14 & Pre-dialysis Product & 10 \\
\hline
\end{tabular}

B

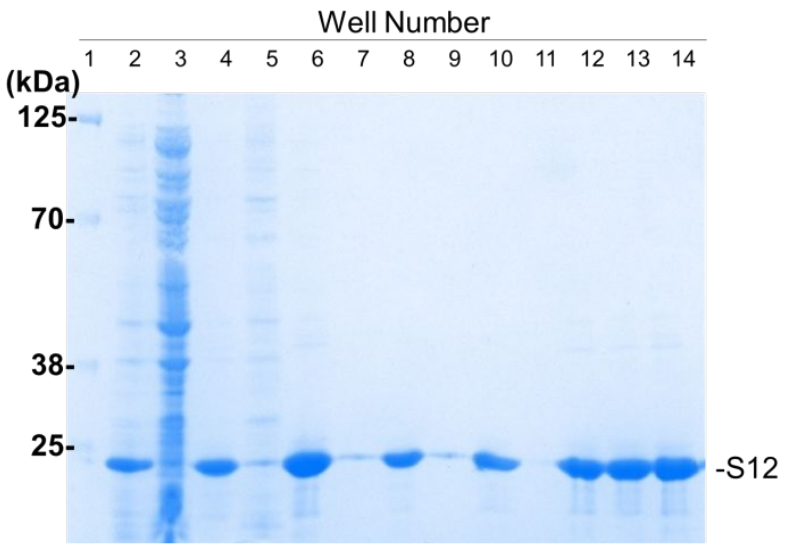

C

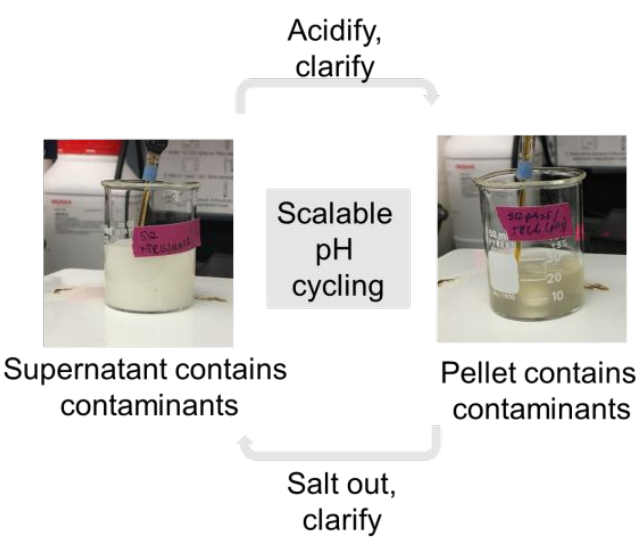

Figure S2. Optimized inclusion body preparation of S12. (A) Well key of SDS-PAGE gel shown in (B). (B) SDS-PAGE of various purification fractions, showing soluble fractions of each step. (C) Photographs of precipitated and solubilized S12 from inclusion bodies, showing the concept of scalable 'pH cycling' for purification of S12. 

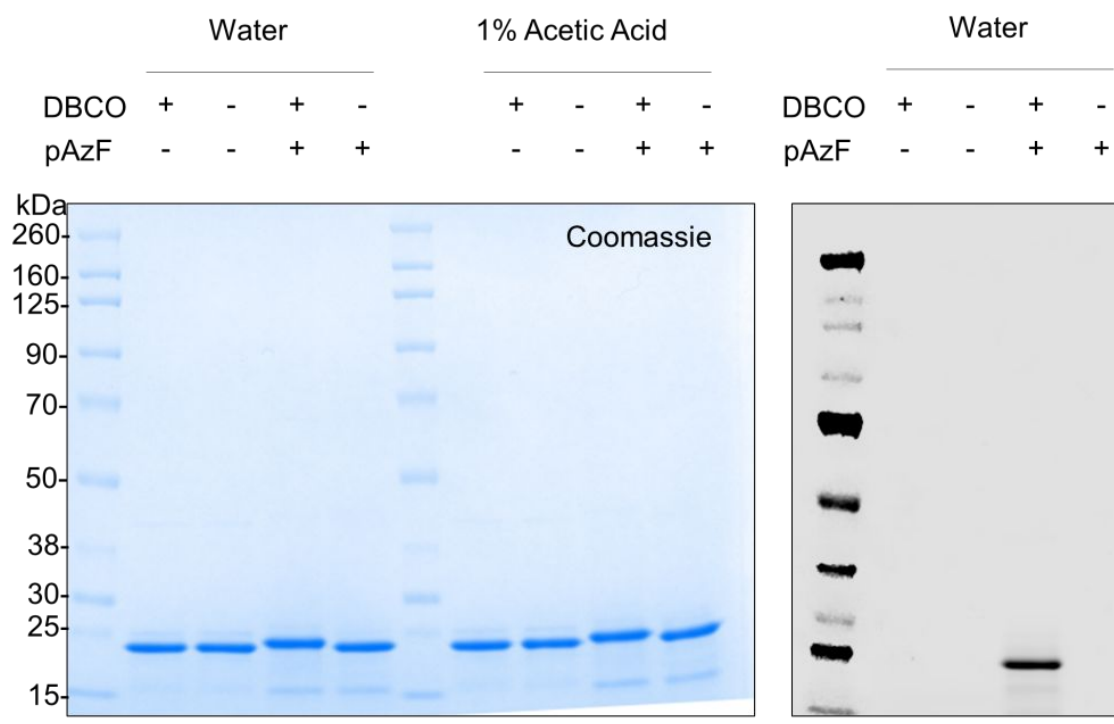

$1 \%$ Acetic Acid

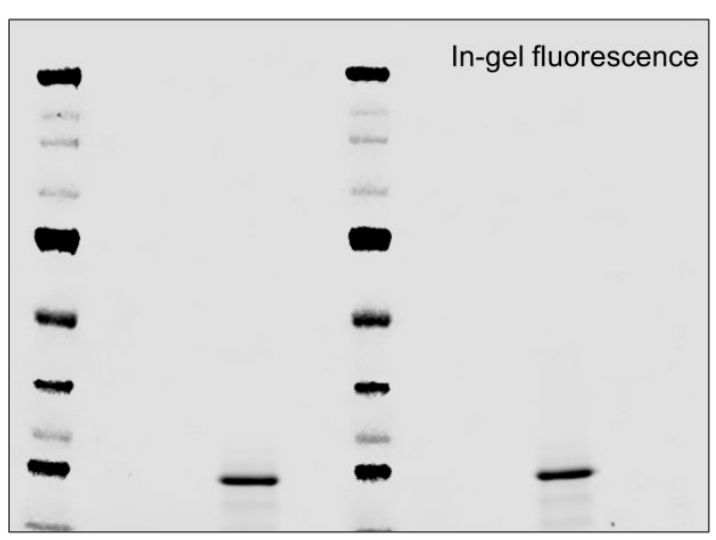

Figure S3. SPAAC reactions proceed in water and in $1 \%$ acetic acid. Coomassie (left) and ingel fluorescence (right) images of SPAAC reaction products. Reactions were run in water or acetic acid as indicated. -/+ pAzF refers to the protein added to the reaction (S12wt or S12$\mathrm{pAzF}$, respectively), and -/+ DBCO refers to the absence or presence of the DBCO-TAMRA probe. 


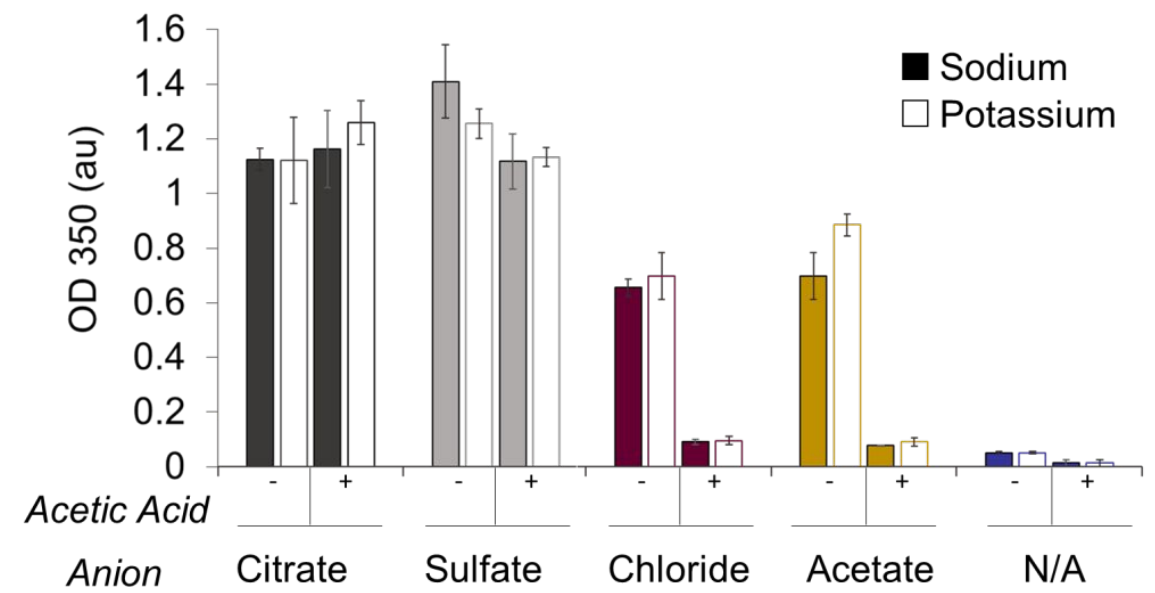

Figure S4. $\mathrm{pH}$-dependence of $\mathrm{S} 12$ solubility in various salts is anion-dependent. Turbidity measurements of S12-pAzF in sodium and potassium salts of various anions (with or without $5 \%$ acetic acid added, indicated with $+/-$ ). Data are averages of $n=3$. Error bars represent the standard deviation between three independent replicates. 
A

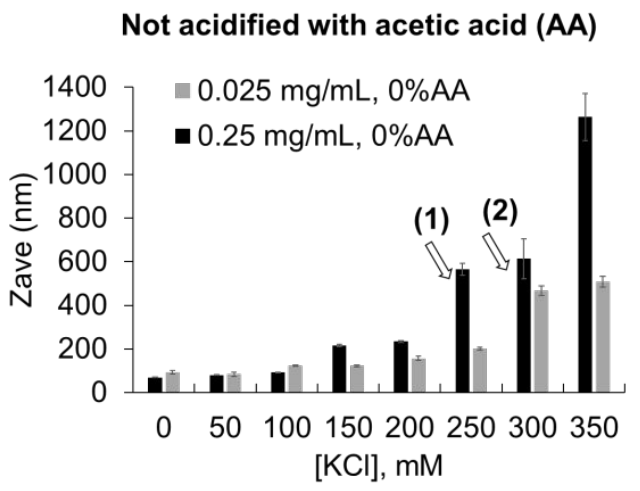

B

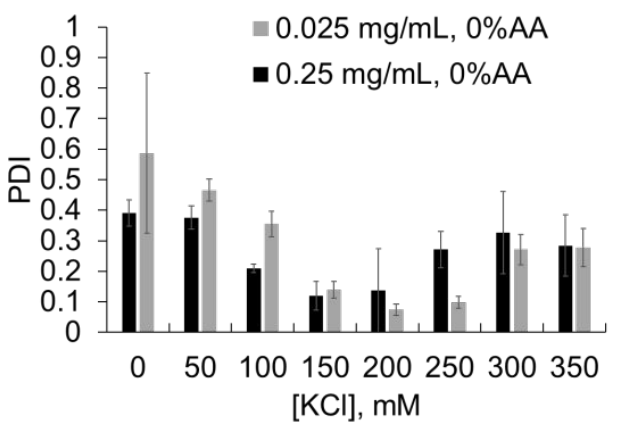

C

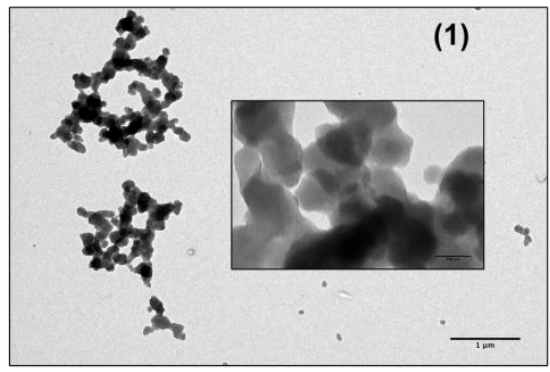

(2)

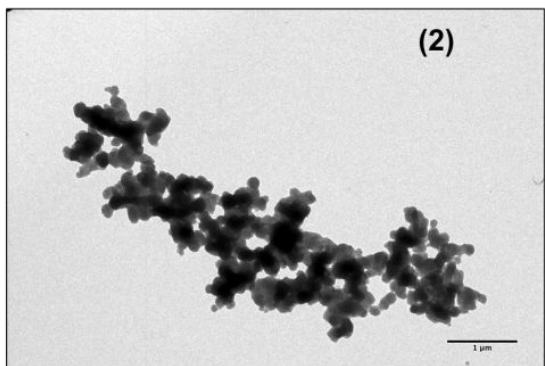

Acidified with acetic acid (AA)
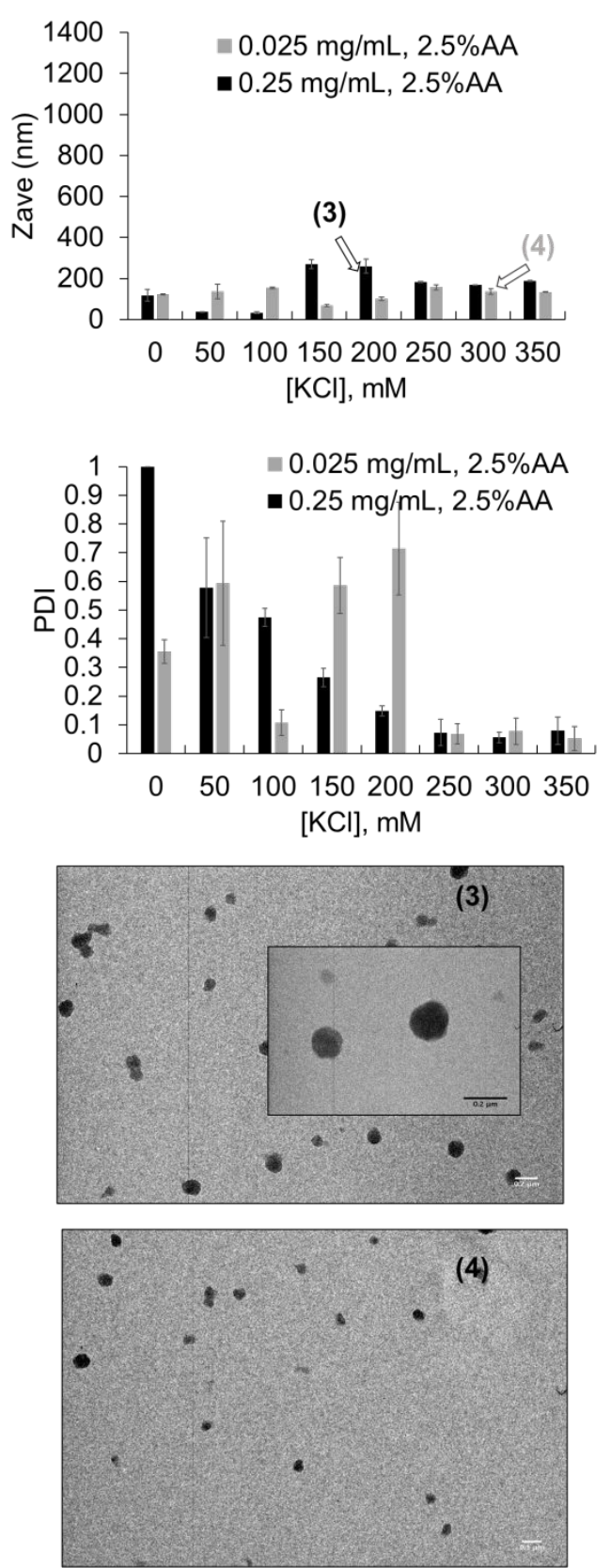

Figure S5. Optimization of NA fabrication conditions. (A) Average diameters (Zave) of S12pAzF particles fabricated at the indicated conditions. DLS was conducted using Zeta Sizer. Error bars represent the standard deviation of three measurements. (B) Associated polydispersity indexes (PDI) of the samples in (A). Error bars represent the standard deviation of three measurements. (C) Selected TEM images of 4 conditions, indicated via numbering and arrows indicating experimental conditions in (A). Conditions (1) and (2) in (C) show DLS and TEM data that are consistent with irregular aggregates. 

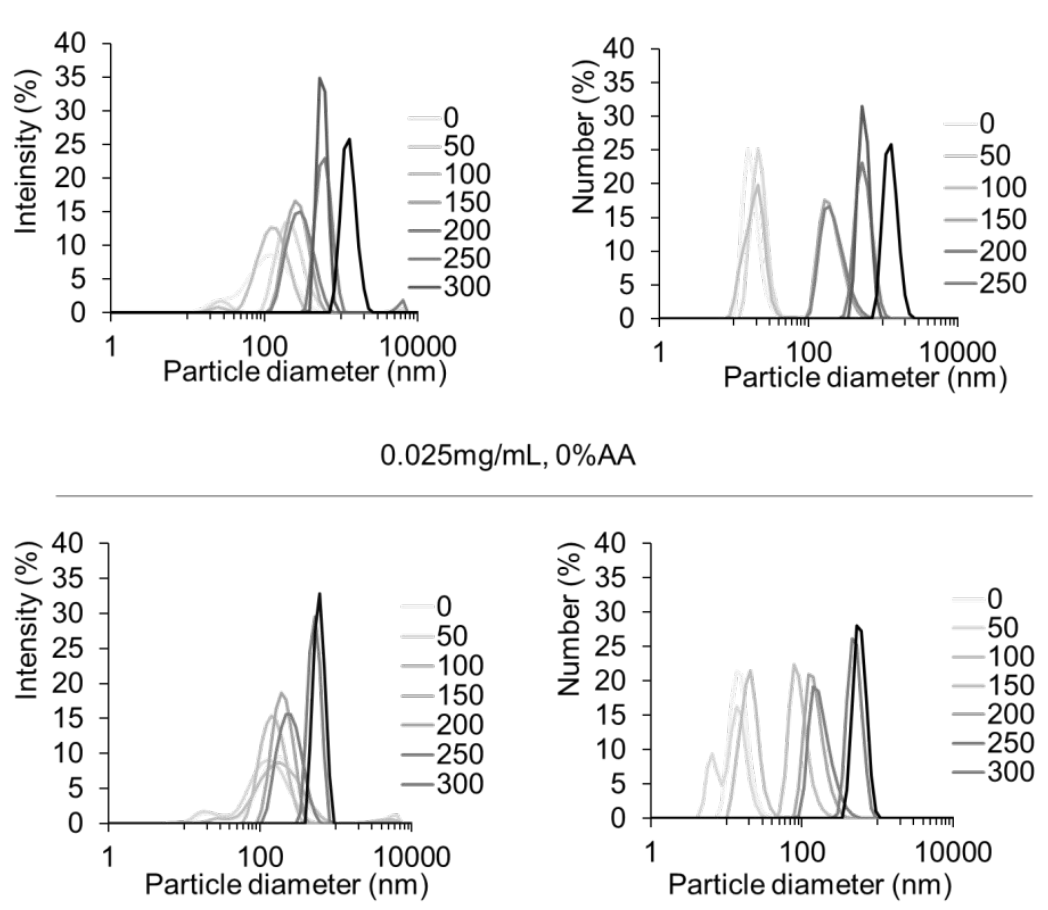

$0.25 \mathrm{mg} / \mathrm{mL}, 2.5 \% \mathrm{AA}$
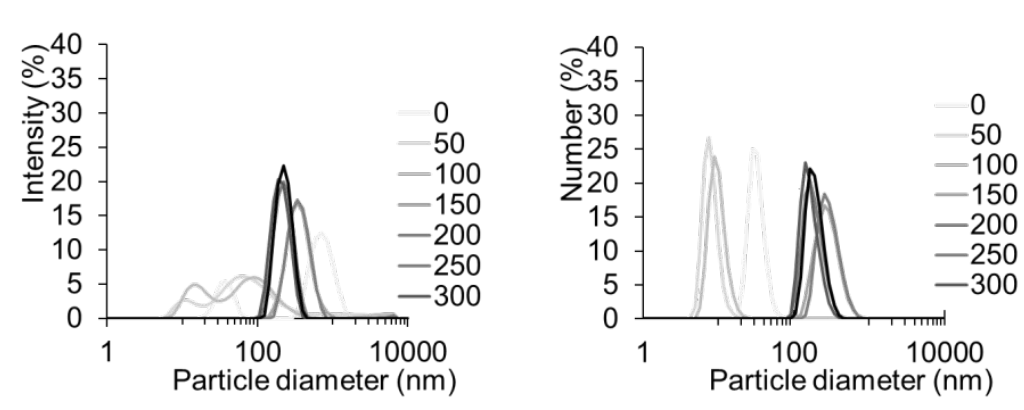

$0.025 \mathrm{mg} / \mathrm{mL}, 2.5 \% \mathrm{AA}$
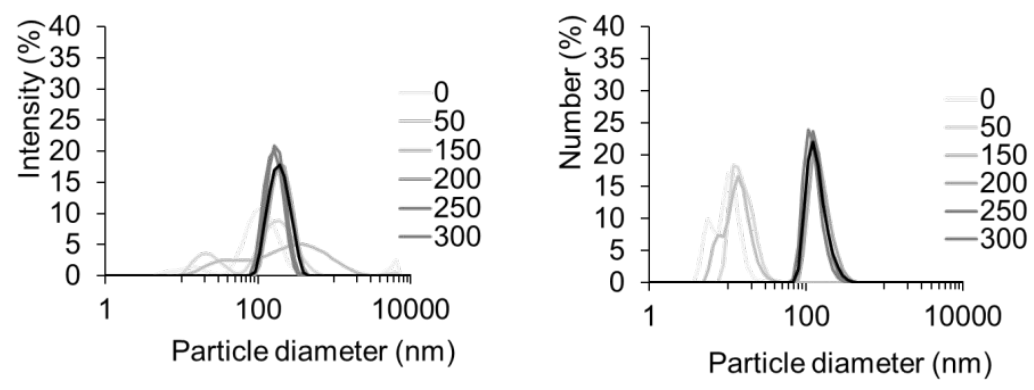

Figure S6. Optimization of NA fabrication conditions, continued. Intensity and number particle size distributions of S12-pAzF particles fabricated at the indicated conditions, measured via Zeta Sizer. 
A

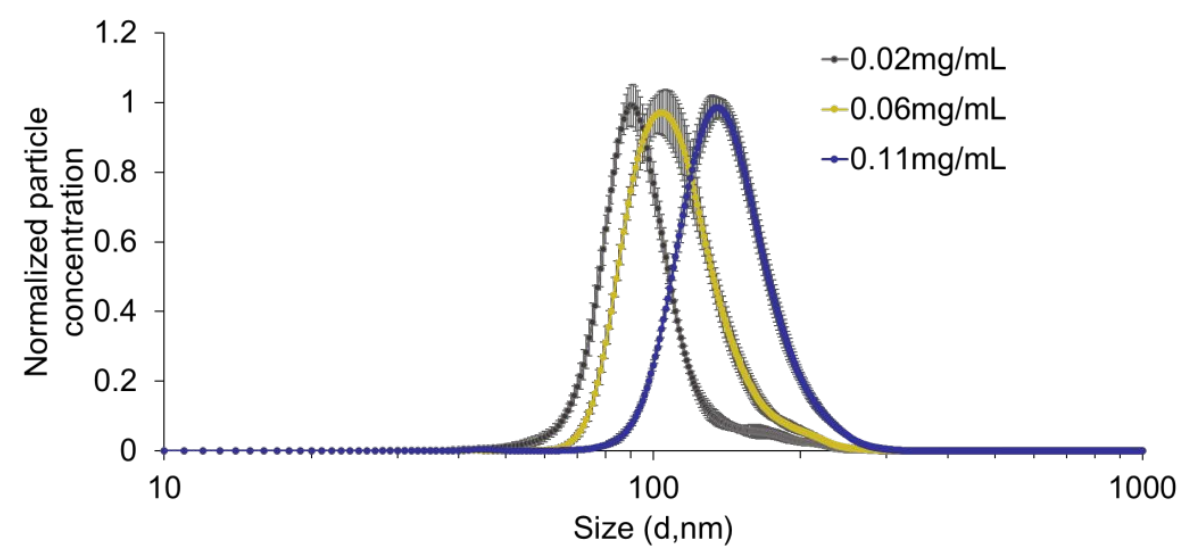

B
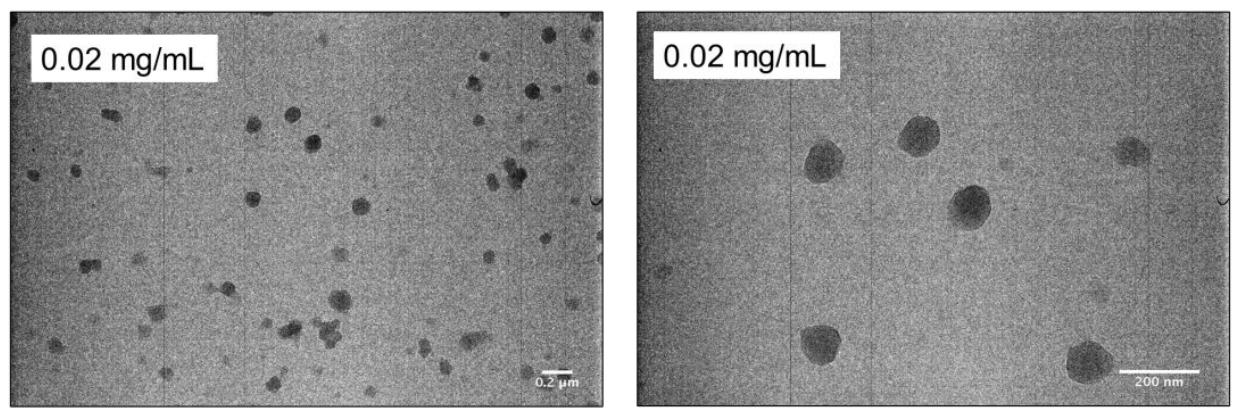

C
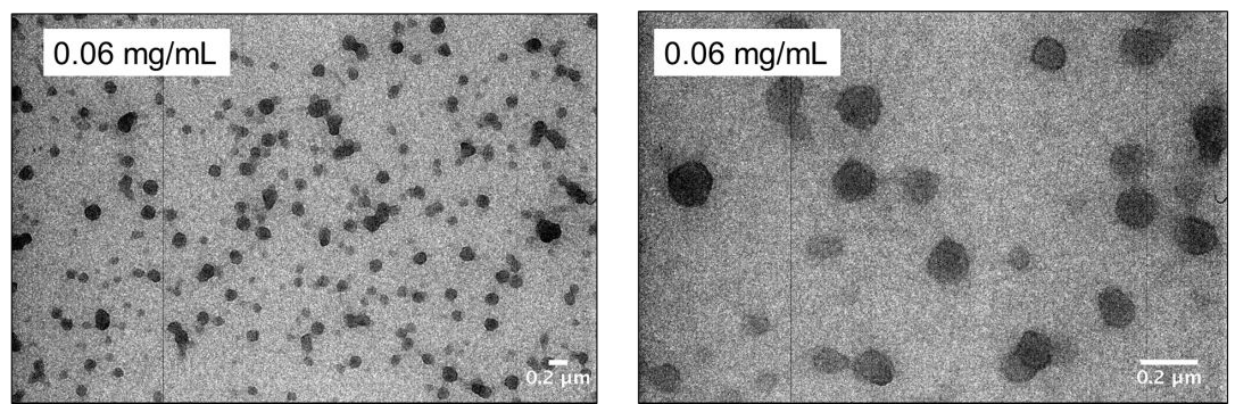

Figure S7. Further characterization of NAs fabricated with optimized conditions. (A) Particle size distributions obtained via NTA. Error bars represent the standard deviation of measurements of three independently prepared batches of NAs. Associated TEM images for NAs made with $0.02 \mathrm{mg} / \mathrm{mL}$ (B) and $0.06 \mathrm{mg} / \mathrm{mL}$ (C) of S12-pAzF. 
A
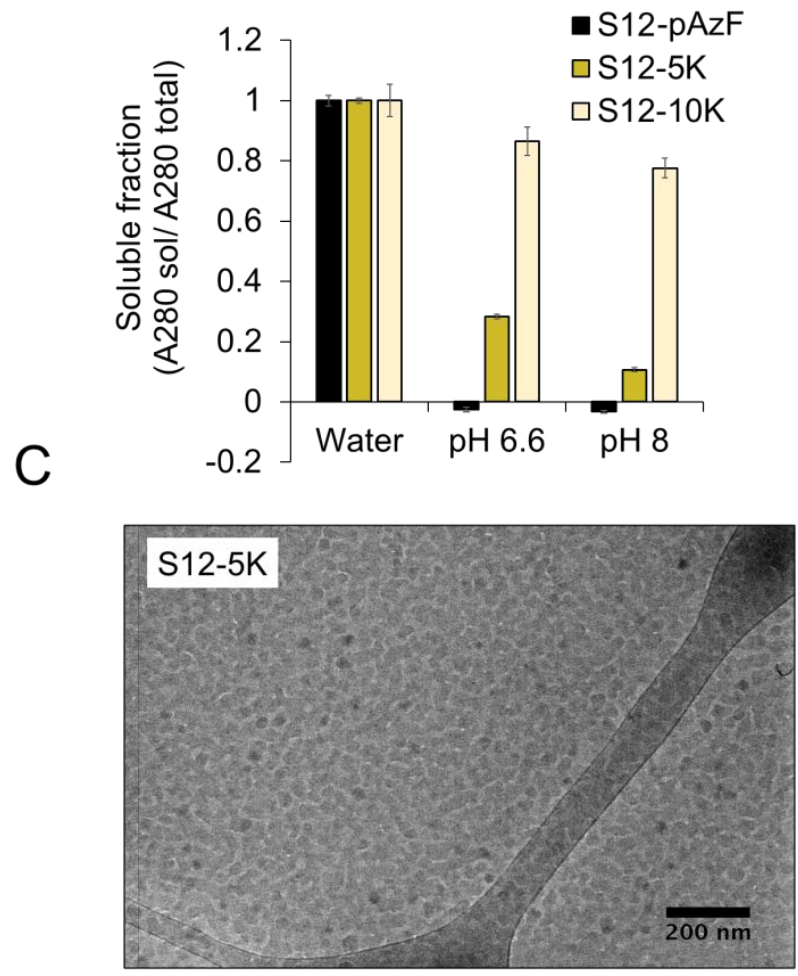

B
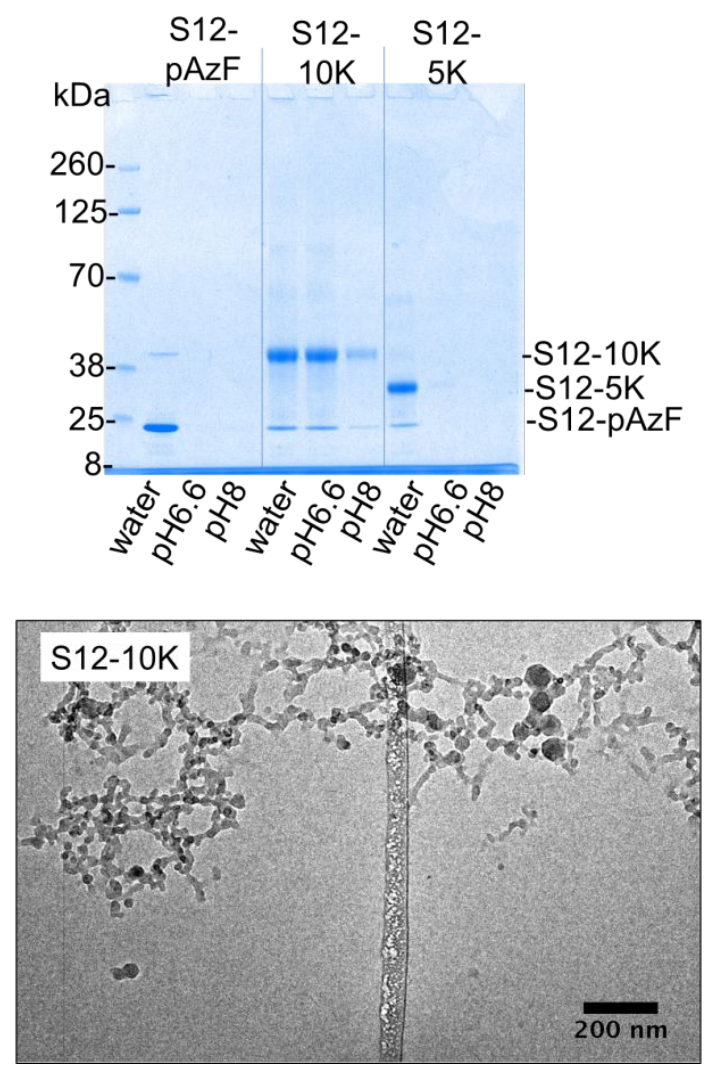

Figure S8. Characterization of S12-PEG conjugates. (A) Soluble (sol) fraction of S12-pAzF, S12-5K, and S12-10K in water, MES pH 6.6, and Tris pH 8. (B) SDS-PAGE analysis of the soluble fractions shown in panel $A$. Annotations indicate which protein construct was added to each well and the associated solvent conditions. CryoTEM images of S12-5K (C) and S12$10 \mathrm{~K}(\mathrm{D})$ in water.

\section{Supporting Information Methods:}

\section{Cryo-TEM}

Cryo-TEM was used to analyze the morphologies of S12-5K and S12-10K PEG conjugates. For cryo-TEM measurement, 200 mesh Cu grids with a lacey carbon membrane (EMS Cat. \# LC200$\mathrm{CU}$ ) were glow discharged as described above. $4 \mu \mathrm{L}$ of sample at $0.5 \mathrm{mg} / \mathrm{mL}$ S12-PEG were pipetted onto the grid and blotted for 5 seconds with a blot offset of $+0.5 \mathrm{~mm}$, followed by immediate plunging into liquid ethane within a FEI Vitrobot Mark III plunge freezing instrument (Thermo Fisher Scientific). The plunge-frozen grids were kept vitreous at $-172{ }^{\circ} \mathrm{C}$ in a Gatan Cryo Transfer Holder model 626.6 (Gatan Inc., Pleasanton, CA, USA) while viewing in a JEOL JEM1230 LaB6 emission TEM (JEOL USA, Inc., Peabody, MA,) at $120 \mathrm{keV}$. Image data was collected by a Gatan Orius SC1000 CCD camera Model 831 (Gatan Inc.). Image analysis was done using Image $\mathrm{J}$. 


\section{Expression of $\mathrm{S} 12$ variants for determining a pAzF mutation position}

Mutants of S12 were cloned using the Q5 Site-Directed Mutagenesis Kit (New England BioLabs) according to manufacturer recommendations. pET28a-S12 was used as the cloning template. Mutations replacing the codons at positions 32, 59, 77 101, 121, 228, and 230 with the amber codon TAG were generated. Plasmids encoding each of the $\$ 12$ mutants were cotransformed with pEVOL-pAzFRS-2.t1 into BL21 Star (DE3) and selected on plates containing 50 $\mu \mathrm{g} / \mathrm{mL}$ Kanamycin and $34 \mu \mathrm{g} / \mathrm{mL}$ Chloramphenicol. For expression, single colonies were selected and grown overnight at $37^{\circ} \mathrm{C}$ in $5 \mathrm{~mL}$ of 2xYTP media supplemented with appropriate antibiotics. Expression cultures were inoculated at OD 0.06 and grown in shake flasks $(50 \mathrm{~mL}$ scale) at 37 ${ }^{\circ} \mathrm{C}$ with antibiotics. For S12-pAzF expression, cultures were supplemented with $0.5 \mathrm{mM}$ IPTG, $0.1 \%(\mathrm{w} / \mathrm{v})$ arabinose, and $3 \mathrm{mM}$ pAzF (Chem-Implex Int'l Inc.) at OD 0.6-0.8. Expression proceeded overnight at $30{ }^{\circ} \mathrm{C}$. Expression cultures were harvested at $5,000 \times \mathrm{g}$ for 15 mins at room temperature. Cells were washed once with Buffer 1 (50 mM Tris, pH 8 and $100 \mathrm{mM} \mathrm{NaCl}$ ), flash frozen with liquid nitrogen, and stored at $-20^{\circ} \mathrm{C}$ until purification. For lysis, cells were thawed on ice for 10 mins and resuspended in $4.5 \mathrm{~mL}$ of Bug Buster Protein Extraction Reagent (Millipore Sigma). Cells were incubated for $20 \mathrm{~min}$ at room temperature on an orbital shaker with constant rotation. Lysozyme was added to a final concentration of $100 \mathrm{ug} / \mathrm{mL}$, followed by sonication. After lysis, purification and LC-MS analysis were conducted as described in the main text. 